\title{
DASHBOARD MANAGEMENT PENJUALAN DAN PEMBELIAN PADA TANGKAHAN IKAN
}

\author{
Arina Prima Silalahi ${ }^{1}$, Harlen Gilbert Simanullang ${ }^{2}$ \\ ${ }^{1,2}$ Universitas Methodist Indonesia \\ Jalan Hang Tuah No. ${ }^{1,2}$ Kota Medan 20151 \\ e-mail :primaarinasilalahi@gmail.com
}

\begin{abstract}
ABSTRAK
Teknologi berperan penting bagi terlaksananya kegiatan manusia saat ini, termasuk dalam kegiatan bisnis dengan berbagai bentuk tampilan/template yang mudah digunakan. Dashboard biasa digunakan untuk menampilkan data secara ringkas. Laporan dapat dilihat secara cepat melalui ringkasan data yang ditampilkan di Dashboard. Pengolahan data yang begitu banyak membuat kegiatan bisnis yang masih melaksanakan pencatatan manual dan melihat runtutan data laporan dirasakan kurang efektif. Pemanfaatan teknologi sangat dibutuhkan pemilik tangkahan ketika menghadapi kendala pengelolaan bisnis seperti waktu yang lama untuk mengelola data, kehilangan data penjualan, pembelian dan terjadinya kesalahan rekapitulasi laporan. Selain itu, kebutuhan akan akses data dan informasi yang cepat dan akurat juga diperlukan untuk mendukung dan memantau pengelolaan usaha. Berdasarkan permasalahan tersebut, perlu solusi untuk memanajemen data penjualan dan pembelian keseluruhan, dan menampilkan laporan secara cepat dan akurat yaitu dengan mengangkat penelitian berjudul "Dashboard Management Penjualan dan Pembelian Ikan pada Tangkahan Ikan”.
\end{abstract}

Kata kunci: Dashboard, Key Performance Indicators (KPI), Tangkahan, Penjualan dan Pembelian

\begin{abstract}
Technology plays an important role in the implementation of human activities today, including in business activities with various forms of display / templates that are easy to use. Dashboards are usually used to display data in a concise manner. Reports can be viewed quickly through a summary of the data displayed on the Dashboard. The large amount of data processing makes business activities that still carry out manual recording and view the order of the report data it is deemed ineffective. The use of technology is very much needed by the owners of tangkahan when facing problems in business management such as a long time in managing data, loss of sales data, purchases and the occurrence of report recapitulation errors. In addition, the need for fast and accurate data and information access is also needed to support and monitor business management. Based on these problems, a solution is needed to manage sales and purchase data as a whole, as well as display reports quickly and accurately, namely by creating a research entitled "Dashboard Management of Sales and Purchasing Fish in Fish Tanks".
\end{abstract}

Keywords: Dashboard, Key Performance Indicators (KPI), Tangkahan, Sales and Purchases

\section{PENDAHULUAN}

Peran serta teknologi dalam kegiatan bisnis sangat diperlukan untuk mendukung kompleksitas dan efektifitas proses bisnis. Dalam hal memanajemen data, teknologi juga dapat dimanfaatkan untuk memudahkan pekerjaan, selain itu untuk mengatur setiap proses bisnis baik penjualan maupun pembelian sehingga dapat menghasilkan informasi yang bermanfaat bagi
pengguna(Simanullang \& Silalahi, 2020). Di era globalisasi ini, setiap perusahaan dituntut untuk memiliki kemampuan mengalokasikan sumber daya perusahaan secara efektif dan efisien. Untuk dapat mencapai hal tersebut informasi yang tepat dan akurat memegang peran penting yang dibutuhkan oleh pihak manajemen perusahaan. Informasi yang tepat dan akurat bisa dengan mudah didapatkan dengan cara pengolahan data 
I N F O R M A I I A

Jurnal Informatika, Manajemen dan Komputer, Vol. 13 No. 1 , Mei 2021

eISSN : 2580-3042

pISSN : 1979-0694

yang baik dan sesuai dengan kebutuhan perusahaan tersebut.

Pengusaha membangun sebuah tempat untuk mendaratkan ikan hasil tangkapan armadanya yang dinamakan dengan tangkahan yaitu tempat pendaratan ikan milik swasta (Saria et al., 2020). Selain menampung produksi, tangkahan juga digunakan sebagai tempat memasarkan ikan ke pasar baik lokal, antar daerah bahkan ekspor. Tangkahan tersebut umumnya memiliki lahan dan fasilitas yang relatif kecil namun aktivitas dan produksi yang relatif besar. Fasilitas yang ada harus dimanfaatkan secara efisien agar aktivitas dan produksi yang besar tersebut dapat ditampung dengan baik di fasilitas yang terbatas.

Dalam kegiatan bisnis sehari-hari pemilik tangkahan ikan melakukan aktivitas penjualan dan pembelian ikan maupun peralatan yang mendukung nelayan untuk menangkap ikan. Mayoritas masyarakat Indonesia memiliki profesi nelayan sebagai matapencaharian, seperti pada daerah pesisir Kabupaten Batubara. Nelayan yang telah berhasil menangkap ikan akan memasok hasil tangkapannya ke tangkahan ikan. Pemilik tangkahan akan menjual ikan dalam jumlah besar. Pada proses pembelian sering terjadi masalah ketika terjadi kekeliruan dalam perhitungan harga pembelian ikan atau barang pendukung lainya, pengelompokan jenis ikan dan barang. Proses penjualan saat ini juga memiliki beberapa kendala sering terjadi kekeliruan ketika melakukan perhitungan penjualan, tidak efisien waktu dalam mencatat banyak data penjualan, data penjualan tidak tersimpan dengan rapi. Selain itu, terdapat masalah seperti rekapitulasi laporan dengan periode tertentu akan menggunakan waktu yang cukup lama, dan catatan yang biasa digunakan untuk mencatat penjualan dan pembelian sering hilang, sehingga kesulitan untuk membuat laporan penjualan dan pembelian pemilik tangkahan.

Dalam proses bisnisnya, pemilik tangkahan berupaya untuk selalu hadir ketika proses pembelian dan penjualan untuk memastikan pendataan proses penjualan dan pembelian berjalan dengan baik. Hal tersebut tentunya mengakibatkan kegiatan lain terbengkalai karena harus menghabiskan waktu di tangkahan. Dengan permasalah tersebut pemilik tangkahan berupaya mencari solusi dengan memanfaatkan teknologi yang dapat memanajemen aktivitas bisnis, yaitu penjualan, pembelian dan laporan yang ditampilkan dengan menarik untuk monitoring setiap saat tanpa harus hadir di tempat dengan cara memanfaatkan konsep dashboard sistem.

Dashboard dapat diartikan sebagai alat yang mampu memvisualisasikan data dan informasi dengan memberikan informasi ataupun kondisi terkini mengenai pencapaian kinerja organisasi berbentuk indikator utama(Permatasari et al., 2020). Dashboard dapat digunakan untuk memonitor keadaan sehari-hari suatu organisasi dan sebagai alat penghubung tunggal yang digunakan untuk membuat keputusan dan mempuyai akses untuk mengunci indikator kinerja(Rahardja et al., 2017). Dashboard didefinisikan sebagai mekanisme penyajian informasi secara visual di dalam sistem manajemen kinerja, yang menyajikan informasi kritis mengenai kegiatan/aktivitas proses operasional secara ringkas(Alexander Wijaya, 2014; Henderi et al., n.d.; Padita et al., 2015).

Berdasarkan level manajemen yang didukungnya, dashboard dibagi menjadi tiga jenis, yaitu level operasional, analitikal/taktikal, dan strategik(Ahn et al., 2019; Gusnadi \& Hermawan, 2020; Saputra \& R, 2021). Ciri khas setiap level dashboard dapat dilihat pada Tabel 1.

Tabel 1 Level Manajemen Dashboard

\begin{tabular}{|c|c|c|}
\hline $\begin{array}{c}\text { Level } \\
\text { Operasional } \\
\end{array}$ & $\begin{array}{c}\text { Level } \\
\text { Analitikal }\end{array}$ & $\begin{array}{c}\text { Level } \\
\text { Strategik }\end{array}$ \\
\hline $\begin{array}{l}\text { Mendukung } \\
\text { manajemen } \\
\text { Level }\end{array}$ & $\begin{array}{l}\text { Mendukung } \\
\text { manajemen } \\
\text { Level }\end{array}$ & $\begin{array}{l}\text { Mendukung } \\
\text { manajemen } \\
\text { Level }\end{array}$ \\
\hline Operasional; & $\begin{array}{c}\text { Analitikal; } \\
\text { Terkhusus } \\
\text { untuk analis, }\end{array}$ & $\begin{array}{c}\text { Analitikal; } \\
\text { Mendukung } \\
\text { untuk }\end{array}$ \\
\hline $\begin{array}{c}\text { Memberika } \\
\text { informasi }\end{array}$ & $\begin{array}{c}\text { level analitikal } \\
\text { dapat } \\
\text { memberi }\end{array}$ & $\begin{array}{l}\text { keputusan } \\
\text { bisnis, } \\
\text { memprediksi }\end{array}$ \\
\hline $\begin{array}{l}\text { tentang setiap } \\
\text { perubahannya }\end{array}$ & $\begin{array}{c}\text { informasi } \\
\text { untuk }\end{array}$ & $\begin{array}{l}\text { peluang, dan } \\
\text { memberikan }\end{array}$ \\
\hline realtime; & $\begin{array}{l}\text { mengetahui } \\
\text { penyebab } \\
\text { suatu } \\
\text { kejadian; }\end{array}$ & $\begin{array}{l}\text { arahan untuk } \\
\text { mencapai } \\
\text { tujuan } \\
\text { strategis; }\end{array}$ \\
\hline $\begin{array}{l}\text { Fokus pada } \\
\text { monitoring } \\
\text { aktivitas dan }\end{array}$ & $\begin{array}{l}\text { Fokus pada } \\
\text { proses analisis }\end{array}$ & $\begin{array}{l}\text { Fokus untuk } \\
\text { mengukur }\end{array}$ \\
\hline $\begin{array}{c}\text { kejadian yang } \\
\text { berubah } \\
\text { secara } \\
\text { kontan; }\end{array}$ & $\begin{array}{l}\text { untuk } \\
\text { menemukan } \\
\text { penyebab } \\
\text { masalah; }\end{array}$ & $\begin{array}{c}\text { kinerja high } \\
\text { level dan } \\
\text { pencapaian; }\end{array}$ \\
\hline $\begin{array}{c}\text { Didesain } \\
\text { untuk } \\
\text { berinteraksi } \\
\text { dengan data. }\end{array}$ & $\begin{array}{c}\text { Tidak didesain } \\
\text { untuk } \\
\text { berinteraksi } \\
\text { dengan data. }\end{array}$ & $\begin{array}{c}\text { Tidak } \\
\text { didesain } \\
\text { untuk } \\
\text { berinteraksi } \\
\text { dengan data. }\end{array}$ \\
\hline
\end{tabular}


I N F O R M A I I A

Jurnal Informatika, Manajemen dan Komputer, Vol. 13 No. 1 , Mei 2021

eISSN : 2580-3042

pISSN : 1979-0694

Informasi yang ditampilkan di dashboard adalah semua data transaksi yang disimpan di dalam basis data. Basis Data juga dapat diartikan sebagai sistem terkomputerisasi yang tujuan utamanya adalah memelihara data yang sudah diolah atau infomasi dan membuat informasi tersedia saat dibutuhkan. Pemanfaatan basis data dilakukan dengan tujuan yaitu kecepatan dan kemudahan, efisiensi ruang penyimpanan, keakuratan, ketersediaan, kelengkapan, keamanan, data dapat dipakai secara bersama (Simanullang \& Silalahi, 2018). Database Management System (DBMS) yang digunakan adalah MySQL karena bersifat open source(Mallisza et al., 2021).

Penelitian ini akan dilakukan perancangan dashboard untuk membantu memanajemen aktivitas pembelian dan penjualan pada tangkahan ikan. Adapun tujuan penelitian ini yaitu (1) Memberikan informasi melalui visualisasi yang baik, (2) membantu pendataan proses pembelian dan penjualan, (3) meningkatkan akurasi dalam pembuatan pelaporan, (4) membantu menyimpan data setiap transaksi, (5) memberikan keakuratan dalam melakukan perhitungan transaksi. Sedangkan manfaat yang dirasakan melalui adanya penelitian ini adalah membantu pemilik tangkahan dalam memantau aktifitas transaksi melalui jarak jauh dan memberikan kemudahan memanajemen penjualan dan pembelian di tangkahan ikan.

Adanya dashboard maka pemilik tangkahan dapat memonitor pencapaian kinerja dalam bentuk indikator-indikator secara cepat dan tepat sehingga pemilik tidak perlu hadir langsung untuk memastikan proses bisnis karena sudah menggunakan koneksi internet. Pada dashboard akan ditampilkan jumlah pembelian, penjualan dan laporan berdasarkan waktu tertentu. Sistem ini juga difungsikan untuk memanajemen penjualan dan pembelian agar mendukung efisiensi waktu dan keakuratan informasi.

\section{METODOLOGI PENELITIAN}

Tahap penelitian merupakan prosedur dalam pencapaian penelitian melalui dua tahapan yaitu pengumpulan data dan pengembangan sistem. Beberapa cara pengumpulan data yang dilakukan peneliti untuk memperoleh keterangan dan penjelasan masalah yang lebih rinci yaitu wawancara, tinjauan pustaka dari beberapa artikel ilmiah/penelitian yang terkait, dan

melakukan pengamatan langsung terhadap prosedur di tangkahan ikan.

Tahapan kedua yaitu pengembangan sistem dengan menggunakan prosedur pengembangan model Waterfall. Model ini melakukan pendekatan secara sistematis dan urut mulai dari level kebutuhan sistem lalu menuju ke tahap analisis, desain, coding, testing/verification, dan maintenance(Silalahi \& Simanullang, 2018).

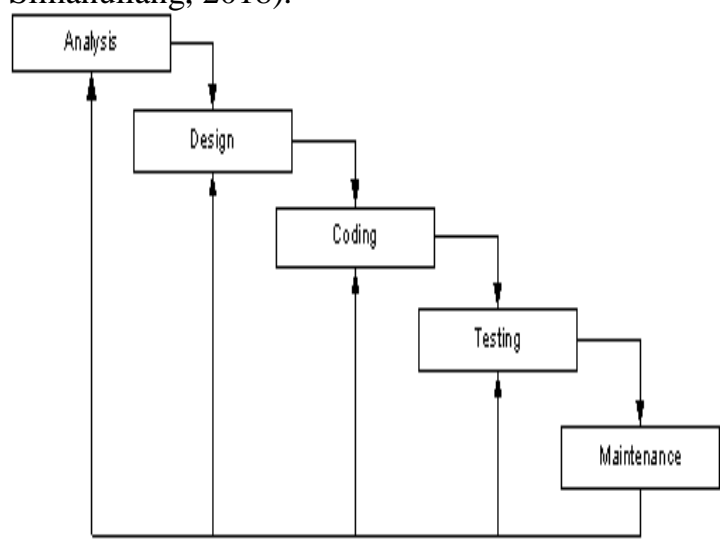

Gambar 1. Siklus metode pengembangan sistem dengan waterfall

Berdasarkan Gambar 1 diatas, proses diawali dengan mencari kebutuhan dari keseluruhan informasi yang akan di aplikasikan dalam bentuk web. Sesuai dengan data yang ada di tangkahan ikan yang dibutuhkan untuk tahap analisis. Analysis dilakukan untuk mengetahui sifat dari program yang akan dibuat, maka harus megetahui fungsi yang akan dibutuhkan, user interface. Tahap ketiga adalah design, untuk mengimplementasikan kebutuhan yang telah disebutkan pada tahap sebelumnya. Pada dua aktivitas sebelumnya, maka proses ini juga harus didokumentasikan sebagai konfigurasi dari web. Tahap keempat adalah coding untuk dapat dimengerti oleh mesin maka desain tadi harus diubah bentuknya menjadi bahasa mesin. Bahasa pemrograman melalui proses coding tahap ini merupakan implementasi dari tahap design yang secara teknis nantinya dikerjakan oleh programmer. Tahap kelima adalah testing untuk menguji coba semua fungsi dalam sistem yang sudah dibangun harus di uji coba agar sistem bebas dari error, dan hasilnya harus sesuai dengan kebutuhan yang sudah didefinisikan sebelumnya. Tahap terakhir adalah maintenance untuk pemeliharaan suatu web diperlukan termasuk di dalamnya adalah pengembangan karena web yang dibuat tidak selamanya hanya seperti itu. 
INFORMA TIK

Jurnal Informatika, Manajemen dan Komputer, Vol. 13 No. 1 , Mei 2021

eISSN : 2580-3042

pISSN : 1979-0694

\section{HASIL DAN PEMBAHASAN}

Pemodelan dalam perancangan sistem digunakan dengan pemodelan UML (Unified Modeling Language) yang berarti bahasa pemodelan standard(Abdillah et al., 2019). UML menyediakan serangkaian gambar dan diagam yang sangat baik sebagai sarana komunikasi antara programmer dengan pengguna. Diagram Use case memiliki komponen pembentuk yaitu (1) Aktor (actor), menggambarkan pihak yang berperan dalam sistem, (2) Use case, aktivitas/sarana yang disiapkan oleh sistem, (3) Hubungan (link), actor manasaja yang terlibat dalam use case ini. Perancangan dashboard management penjualan dan pembelian pada tangkahan ikan dapat dilihat dari diagram Use Case pada gambar 2.

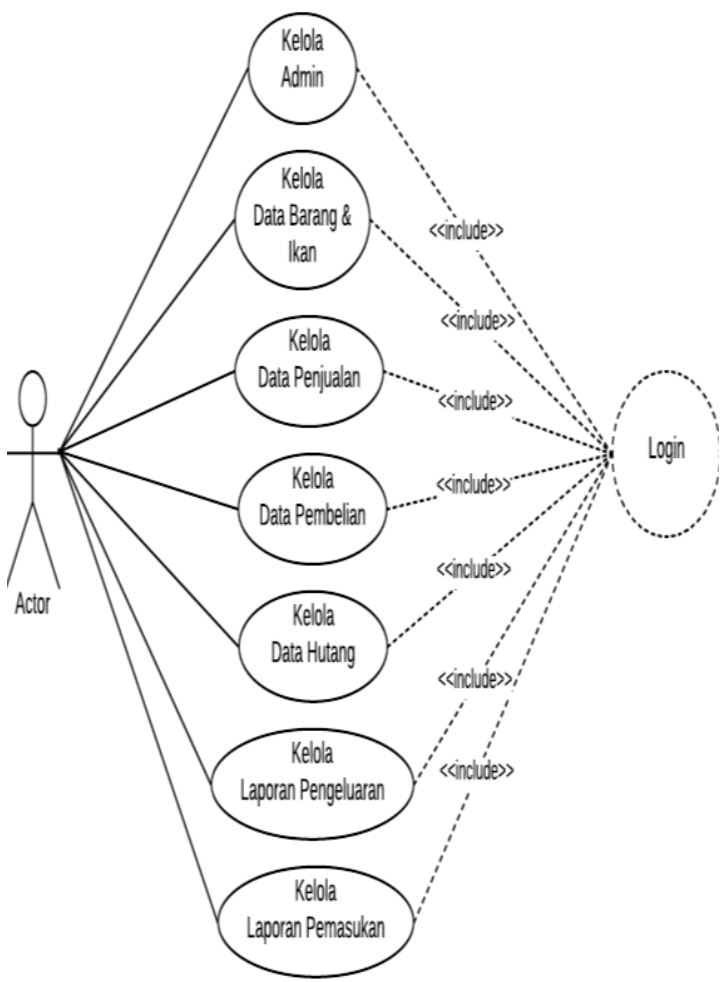

Gambar 2. Diagram Use Case

Class Diagram adalah salah satu jenis diagram yang paling berguna di UML, karena dapat dengan jelas memetakan struktur sistem tertentu dengan memodelkan kelas, atribut, operasi serta hubungan antar objek. Class Diagram menggambarkan serta deskripsi atau penggambaran dari class, atribut, dan objek disamping itu juga hubungan satu sama lain seperti pewarisan, containmet, asosiasi dan lainnya. Class Diagram mampu memberikan pandangan yang lebih luas mengenai suatu sistem

dengan cara menunjukkan kelas serta hubunganhubungannya.

Class Diagram dashboard management penjualan dan pembelian pada tangkahan ikan dapat dilihat pada Gambar 3.

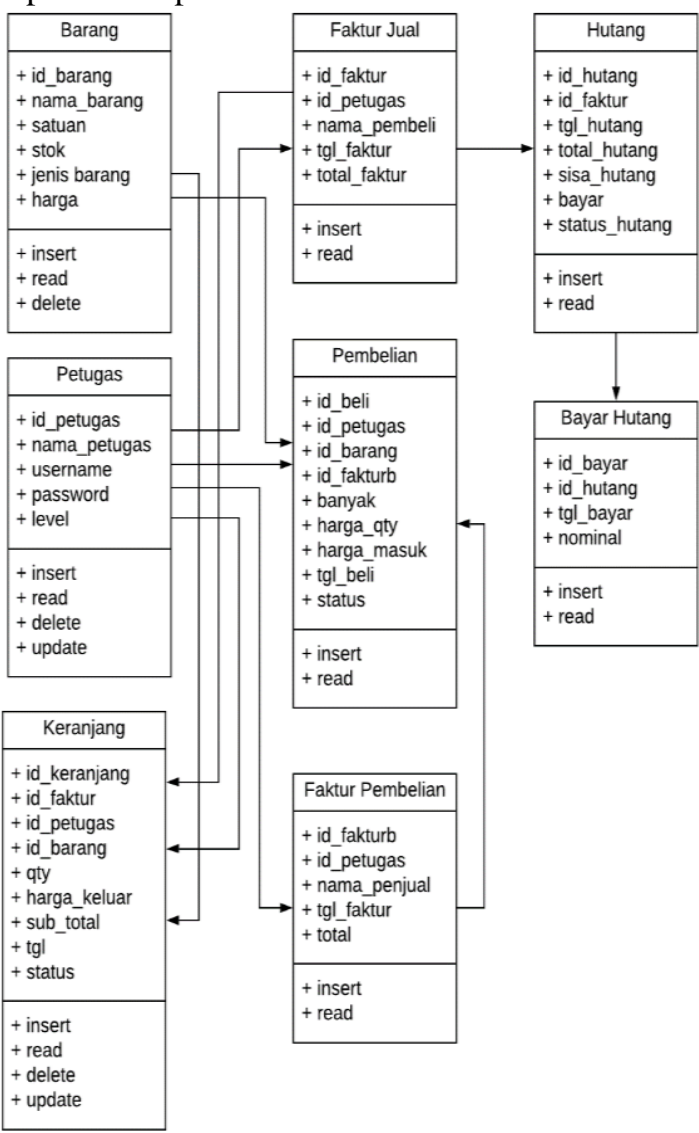

Gambar 3. Class Diagram

Sistem yang berjalan hingga saat ini masih manual, yaitu dengan melakukan pencatatan setiap aktivitas penjualan dan pembelian. Beberapa kendala yang dialami antara lain (1) proses mencatat transaksi penjualan dan pembelian yang cukup rumit, (2) proses penghitungan transaksi yang tidak efisien dan kurang akurat, (3) kesulitan melihat informasi penjualan dan pembelian dengan waktu yang cepat, (4) kesulitan melakukan pelaporan penjualan dan pembelian, (5) seringnya kehilangan buku yang digunakan untuk mendata transaksi, (6) tidak dapat menampilkan informasi dengan visualisasi yang baik, (7) pemilik tangkahan tidak bisa meninggalkan tempat/harus selalu hadir dalam memantau transaksi.

Berdasarkan kendala yang dialami dari sistem yang sedang berjalan, maka dibangun sebuah sistem untuk mengatasi setiap kendala yang ada. Sistem yang dibangun memiliki kelebihan, yaitu (1) Memiliki fasilitas untuk 
IN F ORMA T I K A

Jurnal Informatika, Manajemen dan Komputer, Vol. 13 No. 1 , Mei 2021

eISSN : 2580-3042

pISSN : 1979-0694

pendataan penjualan dan pembelian barang maupun ikan, (2) Dapat melakukan manajemen hutang apabila pembayaran dilakukan dengan tidak tunai, (3) Informasi dihasilkan dengan cepat dan akurat, (4) Mempermudah membuat laporan penjualan dan pembelian, (5) Memiliki visualisasi yang baik dan user friendly, (6) Mengurangi penggunaan kertas atau paperless, (7) Pemilik tangkahan dapat memantau aktivitas/transaksi penjualan dan pembelian tanpa harus berada di tempat.

Tampilan pada halaman utama Dashboard management penjualan dan pembelian pada tangkahan ikan dapat dilihat pada Gambar 4.

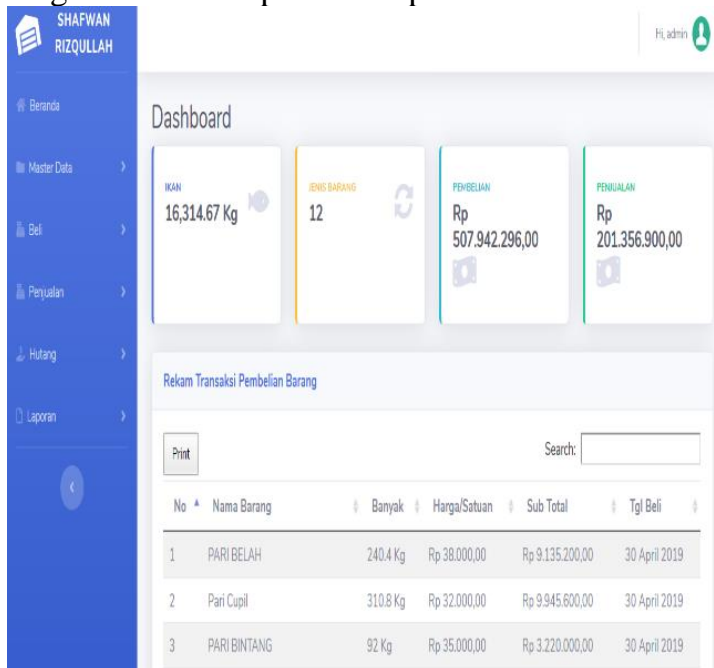

Gambar 4. Tampilan Dashboard management

Pada gambar tersebut dapat dilihat terdapat interface untuk menampilkan data dengan kondisi terkini mengenai data ikan, jenis barang, pembelian dan penjualan.

Tampilan form pembelian ikan dapat dilihat pada Gambar 5.

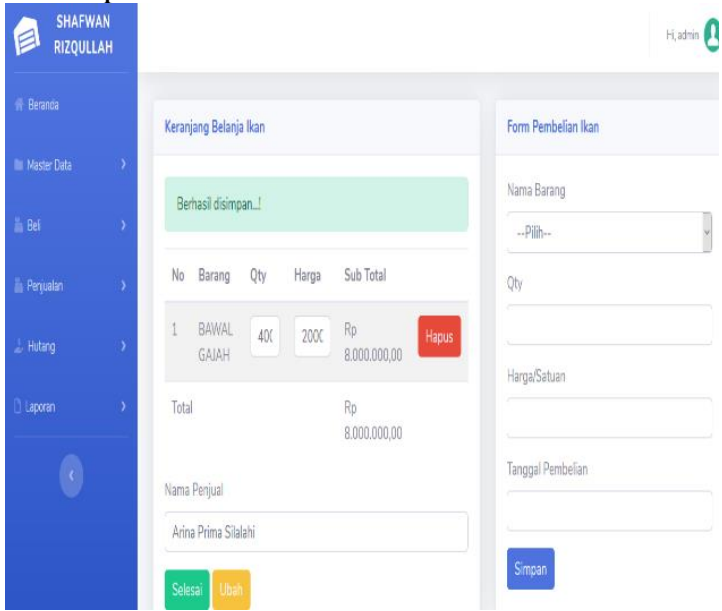

Gambar 5. Tampilan form pembelian ikan

Pada tampilan tersebut terdapat interface form untuk melakukan pendataan pembelian ikan dan kemudian disimpan ke dalam database. Tampilan form penjualan ikan dan barang dapat dilihat pada Gambar 6.

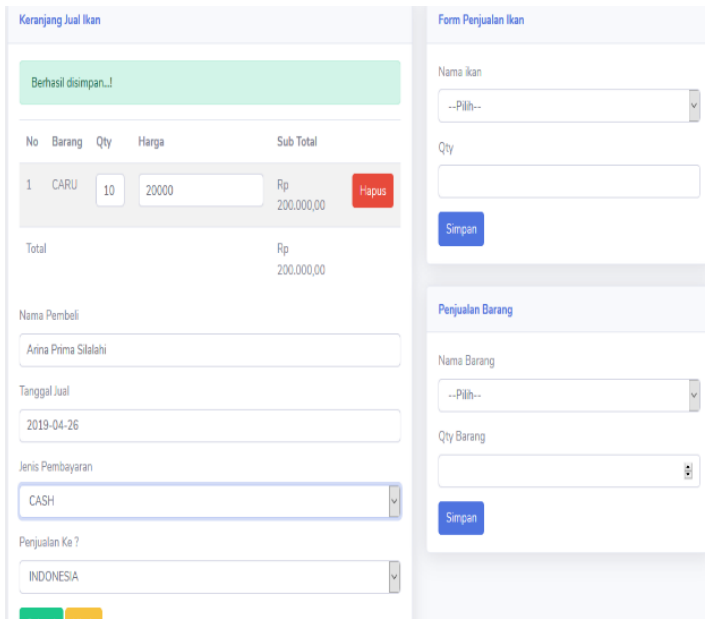

Gambar 6. Tampilan form penjualan ikan dan barang

Pada tampilan tersebut terdapat interface form untuk melakukan pendataan penjualan ikan dan barang, kemudian disimpan ke dalam database. Tampilan laporan pengeluaran dapat dilihat pada Gambar 7.

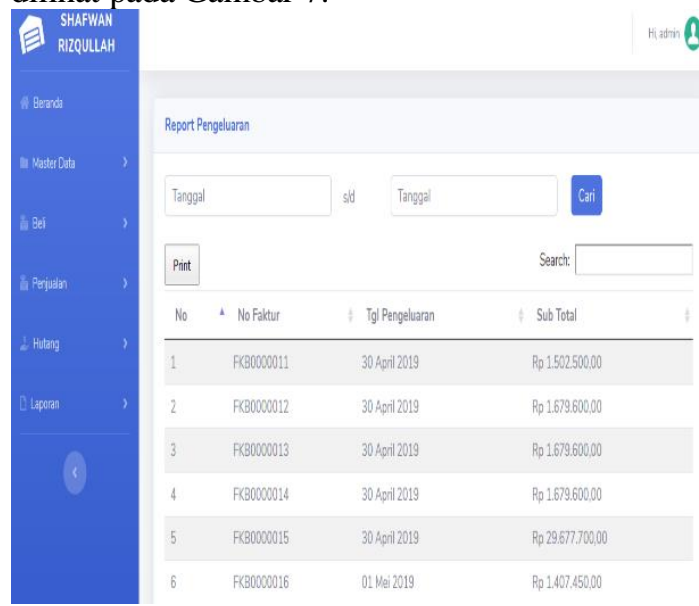

Gambar 7. Tampilan data laporan pengeluaran

Pada gambar tersebut dapat dilihat terdapat interface untuk menampilkan data laporan pengeluaran yang sudah tersimpan di dalam database. 
IN F ORM T I K

Jurnal Informatika, Manajemen dan Komputer, Vol. 13 No. 1 , Mei 2021

eISSN : 2580-3042

pISSN : 1979-0694

\section{KESIMPULAN}

Kesimpulan yang didapatkan adalah

1. Dashboard sistem memberikan alat visualisasi data dan informasi dengan menunjukkan kondisi terkini mengenai pencapaian kinerja transaksi pada tangkahan ikan,

2. Pembuatan pelaporan menjadi lebih baik dan akurat dengan adanya sistem yang dibangun,

3. Sistem memberikan informasi melalui visualisasi yang baik,

4. Sistem dapat membantu pendataan proses pembelian dan penjualan,

5. Sistem membantu menyimpan data setiap transaksi,

6. Pemilik tangkahan dapat memanfaatkan teknologi internet untuk memonitoring perkembangan aktivitas penjualan dan pembelian.

\section{REFERENSI}

Anggraeni, H. D., Saputra, R., \& Noranita, B. (2013). Implementasi Data Mining dengan Metode Algoritma Apriori dalam Menentukan Pola Pembelian Obat (Studi Kasus di Apotek Setya Sehat Semarang). Jurnal Masyarakat Informatika, ISSN: 2086-4930, Vol. 4, No. 7, Hal: 1-8.

Abdillah, R., Kuncoro, A., \& Kurniawan, I. (2019). Analisis Aplikasi Pembelajaran Matematika Berbasis Android dan Desain Sistem Menggunakan UML 2.0. Jurnal Theorems, 4(1), 138-146.

Ahn, E., Liu, N., Parekh, T., Patel, R., Baldacchino, T., Mullavey, T., Robinson, A., \& Kim, J. (2019). Towards early detection of outbreaks of infectious diseases: development of a mobile app and dashboard for outbreaks reporting and analysis (Preprint). JMIR Public Health and Surveillance, 7, 1-16. https://doi.org/10.2196/14837

Alexander Wijaya. (2014). Digital Dashboard Sebagai Solusi Business Intelligence Pada PT.Telkom. 1-15.

Gusnadi, Y., \& Hermawan, A. (2020). Designing Employee Performance Monitoring Dashboard Using Key Performance Indicator (KPI). Bit-Tech, 2(2).

Henderi, Winarno, \& Rahmat, D. (n.d.). Sistem Informasi Eksekutif Dashboard Monitoring Hasil Produksi Pada Pt Kmk Global Sports. 5(1), 58-67.
Mallisza, D., Dakhi, O., Verawadina, U., Siregar, M. I. A., Ekasakti, U., Padang, U. N., Barat, S., Engineering, I., Program, S., \& Medan, U. B. (2021). Design of acceptance information system of new students of national flight vocational high school. 1(10).

Padita, A., Nugroho, H. A., \& Santosa, P. (2015). Model Pengembangan Dashboard Berbasis User-centered Design. Seminar Nasional Ilmu Komputer, Snik, 129-136.

Permatasari, N. T., Tjhe, J. W., Irwansyah, \& Budiyantara, A. (2020). PERANCANGAN DASHBOARD IT STRATEGY PLANNING DAN ARCHITECTURE DENGAN. 2, 165174.

Rahardja, U., Aini, Q., \& Enay, N. (2017). Optimalisasi Dashboard pada Sistem Penilaian Sebagai Media Informasi di Perguruan Tinggi. Sisfotenika, 7(2), 167. https://doi.org/10.30700/jst.v7i2.143

Saputra, E. A., \& R, D. A. (2021). The Implementation of Business Intelligence on Smart Sales Dashboard Using Tableau ( Study Case : PT . Derma Konsep Estetika). 6(1), 223-226.

Saria, F. Y., Pranotob, Y. S., \& Purwasih, R. (2020). ANALISIS USAHA IKAN ASIN (STUDI KASUS DESA REBO KECAMATAN SUNGAILIAT KABUPATEN BANGKA). 2(1), 20-36. https://doi.org/10.33019/jia.v2i1.xxxx

Silalahi, A. P., \& Simanullang, H. G. (2018). Multifactor Evaluation Process (MFEP) untuk Rekomendasi Jurusan pada Sekolah Menengah Atas. METHODA, 8(1), 84-91.

Simanullang, H. G., \& Silalahi, A. P. (2018). Algoritma Blowfish Untuk Meningkatkan Keamanan Database Mysql. 4(1), 10-14.

Simanullang, H. G., \& Silalahi, A. P. (2020). Sistem Kuesioner Penilaian Kinerja Guru Menggunakan Metode Multifactor Evaluation Process (MFEP) Pada SMP Negeri 3 Binjai. Jurnal Informatika Kaputama(JIK), 4(2), 149-157. 